\title{
CONFIGURATION OF THE METHOXYIMINO GROUP AND PENETRATION ABILITY OF CEFOTAXIME AND ITS STRUCTURAL ANALOGUES
}

\author{
Alessandro Costa and Giuseppe A. Botta \\ Istituto di Microbiologia, Università di Genova \\ Viale Benedetto XV, 10, 16132 Genova, Italy
}

(Received for publication March 7, 1983)

\begin{abstract}
Among the different mechanisms by which bacteria are resistant to $\beta$-lactam antibiotics, three are of major interest: production of $\beta$-lactamase, modifications of the target penicillinbinding proteins (PBPs) and decreased permeability. Cefotaxime (CTX) is a recently synthesized cephalosporin derivative, active against $\beta$-lactamase producing Gram-negative bacteria and possessing in the acylamino side chain a methoxyimino group in the syn-configuration. It has been compared for affinity to PBPs and penetration ability with its isomer possessing the same group in the anti-configuration and the corresponding demethoxyimino derivative.

The anti-isomer, although resistant to $\beta$-lactamase, is devoid of antibacterial activity (MIC for Escherichia coli higher than $500 \mu \mathrm{g} / \mathrm{ml}$ ). The affinities of CTX and its analogues for the PBPs of several strains of $E$. coli have been determined in vivo and in vitro by competition experiments using intact cells and bacterial envelopes, respectively. Only minor differences in the affinity for the target PBPs were detected in vitro.

However, in vivo studies proved that the $50 \%$ saturating concentrat:ons for the PBPs were more than 100-fold higher for the anti-isomer than for CTX.

The reported results suggest that a very simple structural modification of the CTX molecule greatly decreases the penetration ability of the antibiotic through the outer cell layers, thus dramatically affecting its antibacterial properties.
\end{abstract}

Cefotaxime (HR 756; 7-\{2-(2-amino-4-thiazolyl)-2-[( $Z$ )-methoxyimino]acetamido\}cephalosporanic acid) is a highly active broad spectrum cephalosporin derivative ${ }^{1,2)}$ and may be considered resistant to hydrolysis by penicillinases and cephalosporinases ${ }^{3}$. With both types of enzymes the behavior of the isomer with the methoxyimino group in the anti-configuration (RU 25328) is very similar to that of cefotaxime, but this structural analogue lacks antibacterial activity.

The compound without oxime (RU 7-23345) possesses a slightly lower antibacterial activity than cefotaxime, but appears as a good substrate for the $\beta$-lactamases ${ }^{3)}$. The structural formulas of these compounds are shown in Fig. 1.

The antibacterial activity of $\beta$-lactam antibiotics against Gram-negative bacteria depends upon: a) resistance to periplasmically located $\beta$ lactamase; b) ability to penetrate the permeability barrier of the outer membrane and c) affinity for essential penicillin-binding proteins (PBPs) located in the cytoplasmic membrane.
Fig. 1. Structure of cefotaxime and its analogues.<smiles>CON=C(c1ccc(Cl)cc1)c1csc(N)n1</smiles>

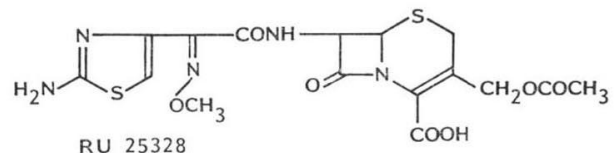<smiles>CC(=O)CC1=C(C(=O)O)N2C(=O)C(NC(=O)Cc3csc(Br)n3)C2SC1</smiles> 
Because the differences in the antibacterial activity of cefotaxime and its anti-isomer are not related to differences in the susceptibility to $\beta$-lactamases, we have investigated which one of the other two mechanisms (decreased affinity or decreased permeability) was more relevant in determining the above described properties.

The binding affinities of the three compounds have been determined in PBPs competition experiments using both envelopes from sonicated bacteria and intact growing cells. Since the permeability barrier present in intact cells is non-operative in the in vitro assay system ${ }^{4,5,8)}$, a comparison between the observed affinities under the two experimental conditions is a reliable indication of the ability of the antibiotic molecules to penetrate the outer membrane ${ }^{7,8}$.

\section{Materials and Methods}

Bacterial Strains and Growth Conditions

Escherichia coli $\left.\mathrm{KN} 126^{9}\right)$, E. coli $\mathrm{BUG} 6^{10,11)}$, a thermosensitive division mutant, and E. coli SP $45^{11,12)}$, a $p b p A$ temperature sensitive mutant, were used. Strains were grown in Antibiotic Medium No. 3 (Difco) at 30 and $42^{\circ} \mathrm{C}$.

\section{In Vivo Competition Binding Experiments}

Exponentially growing cells (1 liter cultures) were divided into aliquots $(80 \mathrm{ml}$ each) and treated (15 minutes) with serial dilutions of the antibiotic to be tested (ranging from 100 to $0.78 \mu \mathrm{g} / \mathrm{ml}$ ). Cells were immediately washed with cold phosphate buffer $(50 \mathrm{~mm} ; \mathrm{pH} 7)$, and envelopes were prepared by differential centrifugation of sonicated cells and subsequently incubated with the radiolabelled antibiotic $\left(\left[{ }^{14} \mathrm{C}\right]\right.$ benzylpenicillin or $\left[{ }^{125} \mathrm{I}\right]$ furazlocillin) as described below.

In Vitro Competition Binding Experiments

Envelopes were prepared from sonicated cells harvested in the exponential phase of growth (1 liter cultures). After sonication (Labsonic Mod. 1510, Braun Co., West Germany), intact cells were pelletted by centrifugation $(3,000 \times g$ for 10 minutes), and the supernatant containing the membrane fraction was centrifuged at $100,000 \times g$ for 30 minutes. Envelopes were divided into ten samples and resuspended in $50 \mu \mathrm{l}$ of $50 \mathrm{~mm}$ phosphate buffer. For the in vitro competition experiments, serial dilutions of the antibiotic to be tested (ranging from 100 to $0.78 \mu \mathrm{g} / \mathrm{ml}$ ) were added to the envelope suspensions and incubation carried out for 15 minutes at the temperature of growth $\left(30\right.$ or $\left.42^{\circ} \mathrm{C}\right)$. Thereafter the radiolabelled antibiotic $\left(\left[{ }^{14} \mathrm{C}\right]\right.$ benzylpenicillin or $\left[{ }^{125} \mathrm{I}\right]$ furazlocillin) was added at saturating concentrations, and incubation was continued for an additional 15 minutes.

In the in vivo competition experiments the treatment of envelopes with the unlabelled antibiotic was obviously omitted.

When $\left[{ }^{14} \mathrm{C}\right]$ benzylpenicillin was used, the reaction was terminated by adding sarkosyl $(2 \%$ final concentration) containing $100 \mathrm{mg} / \mathrm{ml}$ of unlabelled benzylpenicillin.

When [ ${ }^{125}$ I] furazlocillin was used, the reaction was terminated by adding an excess of unlabelled benzylpenicillin. Membranes were then washed and resuspended in sarkosyl ( $2 \%$ final concentra(tion) $)^{14)}$.

Separation of PBPs by SDS-PAGE and Autoradiography

After extraction (30 minutes at room temperature) and centrifugation (100,000 $\times g$ for 30 minutes), the solubilized proteins were mixed with sample buffer ${ }^{9}$ and heated at $100^{\circ} \mathrm{C}$ for 4 minutes. The radiolabelled PBPs were separated in a discontinuous buffer system ${ }^{15}$ ) on a $7.5 \%$ acrylamide $-0.15 \%$ bisacrylamide slab gel.

When $\left.{ }^{[125} \mathrm{I}\right]$ furazlocillin was used, PBPs were detected after overnight exposure of the gels to X-ray films at $-70^{\circ} \mathrm{C}$ or, when $\left[{ }^{14} \mathrm{C}\right]$ benzylpenicillin was used, the gels were prepared for fluorography by the procedure of BONNER and LASKEY ${ }^{16,17)}$ with the modification that $\mathrm{EN}^{3} \mathrm{HANCE}$ (New England Nuclear) was used instead of DMSO-PPO. Dried gels were exposed to X-Omat film SO-282 (Kodak) for at least 40 days. 


\section{Results}

As known from in vitro competition binding assays, the essential PBPs for which cefotaxime has the highest affinity are PBP-3 and PBP-1A ${ }^{3,8}$.

Under our experimental conditions, the in vitro $50 \%$ saturating concentrations of cefotaxime for its primary targets were almost identical for the different $E$. coli strains tested. Values were close to $0.78 \mu \mathrm{g} / \mathrm{ml}$ for PBP-1A and lower than $0.1 \mu \mathrm{g} / \mathrm{ml}$ for PBP-3, in agreement with previously published results $^{8)}$ (data not shown).

When intact cells growing at $30^{\circ} \mathrm{C}$ were treated with serial dilutions of cefotaxime for a 15 -minute pulse, the values of the $50 \%$ saturating concentrations were very similar to those obtained when the antibiotic was added to envelope suspensions (Fig. 2).

However, in vivo, the complete saturation of PBP-1A was not obtained even at concentrations of cefotaxime up to $100 \mu \mathrm{g} / \mathrm{ml}$ (Fig. 2). On the contrary, when the binding assay was performed in vitro, complete disappearance was obtained with $0.8 \mu \mathrm{g} / \mathrm{ml}$. These results suggest that PBP-3 is the only target of effective concentrations of cefotaxime in intact growing cells.

The compound without oxime (RU 7-23345) possesses the same primary targets as cefotaxime both in vitro (data not shown) and in intact cells (Fig. 3). The MIC values were only slightly higher than those observed for cefotaxime against the strains tested $(6.25$ and $1.56 \mu \mathrm{g} / \mathrm{ml}$, respectively). Indeed, in both experimental situations, the affinity of RU 7-23345 for PBP-3 is somewhat lower $(50 \%$ saturating concentration close to $0.2 \mu \mathrm{g} / \mathrm{ml}$ ) than that of cefotaxime (less than $0.1 \mu \mathrm{g} / \mathrm{ml}$ ). The two compounds show the same affinity for PBP-1A.

On the basis of these results, the poorer antibacterial activity of RU 7-23345 might be due, besides

Fig. 2. Competition of cefotaxime for $\left.{ }^{125} \mathrm{I}\right] \mathrm{furazlocillin}$ binding in intact growing cells (in vivo competition).

Samples $(80 \mathrm{ml})$ of exponentially growing $E$. coli $\mathrm{KN} 126$ were treated for 15 minutes with concentrations of cefotaxime ranging from 100 (N) to 0.097 (B) $\mu \mathrm{g} / \mathrm{ml}$ (1:1 dilutions; $\mathrm{A}=$ untreated control.)

Membranes were prepared by differential centrifugation of sonicated cells and incubated with [ $\left.{ }^{125} \mathrm{I}\right]$ furazlocillin for 15 minutes (see Materials and Methods). After extraction with sarkosyl, proteins were separated by SDS-PAGE (acrylamide - bisacrylamide, 30: 0.6, $7.5 \%$ gel). Bands were detected by autoradiography.

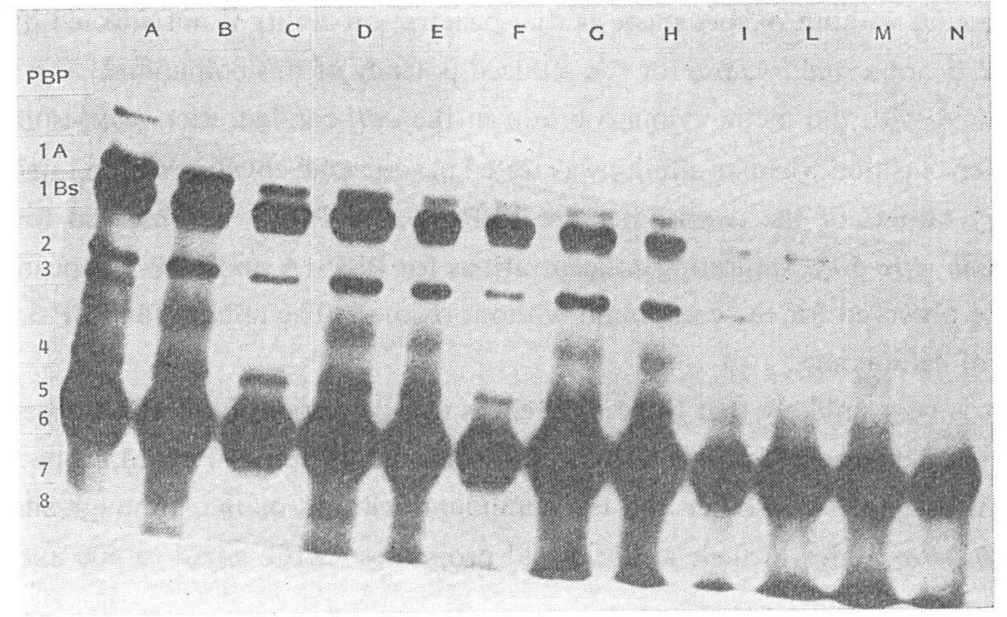


Fig. 3. Competition of the anti-isomer of cefotaxime for $\left[{ }^{14} \mathrm{C}\right]$ benzylpenicillin binding in membranes (in vitro competition).

Samples of membranes were incubated with buffer (A) or with increasing concentrations of the anti-isomer ranging from 0.78 (B) to 100 (I) $\mu \mathrm{g} / \mathrm{ml}$ (1: 1 dilutions). For further details see Materials and Methods.

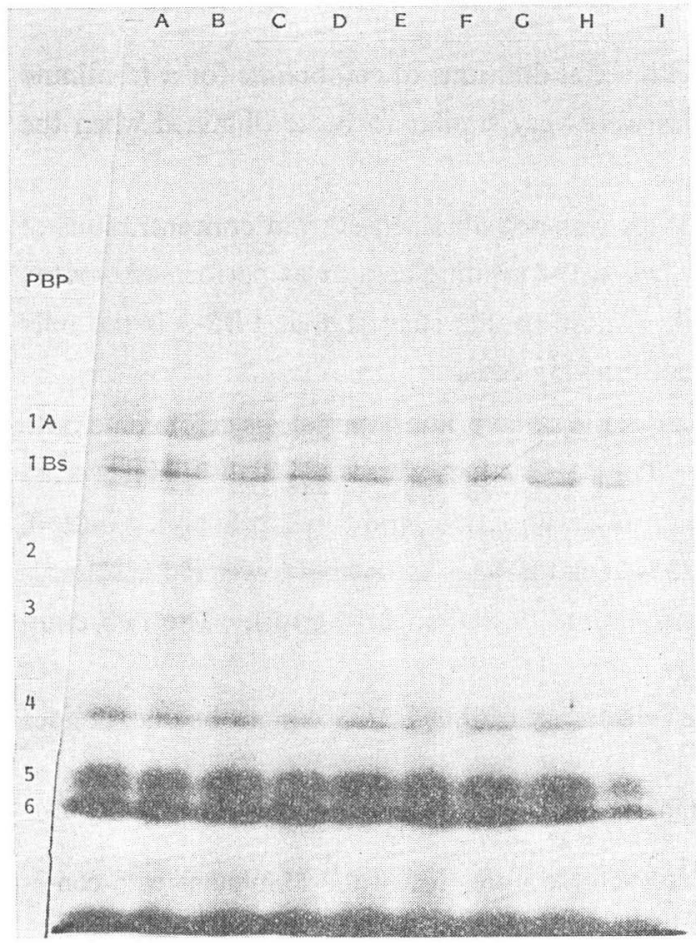

Fig. 4. Competition of the anti-isomer of cefotaxime for $\left[{ }^{14} \mathrm{C}\right]$ benzylpenicillin binding in intact growing cells (in vivo competition).

Samples $(80 \mathrm{ml})$ of exponentially growing $E$. coli $\mathrm{KN} 126$ were treated for 15 minutes with concentrations of the anti-isomer ranging from 0.78 (B) to $100(\mathrm{I}) \mu \mathrm{g} / \mathrm{ml}$ (1: 1 dilutions; $\mathrm{A}=$ untreated control). *Failing in solubilization or in migration. For further details see Materials and Methods.

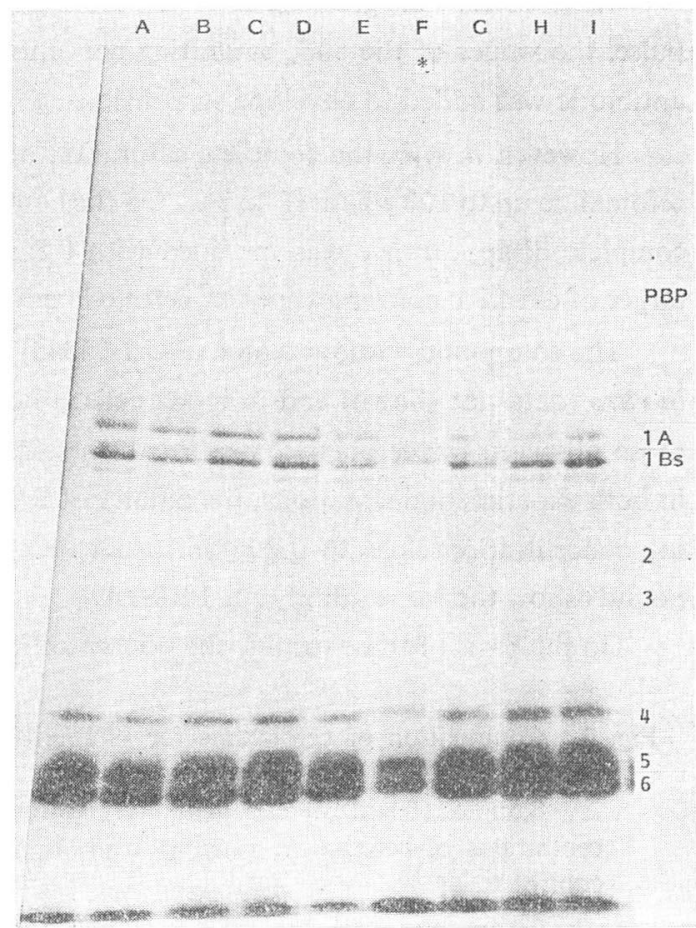

its sensitivity to the $\beta$-lactamases, to the observed decreased affinity to one of the functionally major PBPs. The similarity of the results obtained with sonicated envelopes and intact growing cells, when testing the compound without oxime, suggests that penetration ability is not affected by this structural modification and is not a major cause for the reduced potency of this compound.

The compound with the methoxyimino group in the anti-configuration (anti-isomer) behaved in a clear-cut different fashion when its affinity was tested in sonicated envelopes or in intact growing cells.

The primary targets of the anti-isomer are PBP-1A and PBP-3 as observed for the structural analogues. The in vitro $50 \%$ saturating concentrations for PBP-1A and PBP-3 appeared to be almost identical to those observed for the compound without oxime. The affinity for PBP-3 is $20 \sim 40$ times lower than that of cefotaxime.

However, it is very unlikely that these differences can be responsible for the observed differences in the MICs values between cefotaxime and its anti-isomer $(1.45$ and $400 \mu \mathrm{g} / \mathrm{ml}$, respectively). Moreover, it is evident that the anti-isomer and the compound without oxime, although showing the same binding profile in vitro, differ in their antibacterial properties (MICs equal to 400 and $6.25 \mu \mathrm{g} / \mathrm{ml} \mathrm{re-}$ spectively). 
More significant is the complete lack of binding ability (up to $100 \mu \mathrm{g} / \mathrm{ml}$ ) for the target PBPs of the anti-isomer when tested in intact growing cells (Fig. 4). As evident from this autoradiogram, the anti-isomer does not compete in vivo for any of the PBPs although very high concentrations were used.

\section{Discussion}

A necessary condition for bacterial killing by $\beta$-lactam antibiotics is the ability to reach the PBPS in the inner membrane. In Gram-negative bacteria they have to pass through the permeability barrier represented by the outer membrane ${ }^{4)}$. Among the several reported assays to test $\beta$-lactam permeability $y^{4,5}, 7$, the comparison between the in vitro and in vivo (intact cells) affinities for the PBPs has recently been shown to give direct evidence of the ability of the $\beta$-lactam antibiotics to again access to their targets (references 6, 8, 19 and M. G. Boulton, personal communication). Indeed, when the binding is performed in vivo i.e. in intact growing cells in the presence of the antibiotic, the experimental condition are suitable for permeability studies, even more when non $\beta$-lactamase producing strains or $\beta$-lactamase resistant antibiotics are used.

On the contrary, in vitro binding assay gives information only on the affinity of the molecule for the PBPs, but not on the possible influences of permeability on the binding in the intact cells. Indeed, it is likely that the results obtained with partially purified envelopes can be affected by the orientation of the vesicles formed when cells are broken by sonication or by the French pressure cells. FUTAI ${ }^{20)}$ has demonstrated that these vesicles are inside-out. He concluded, by using different assays to determine orientation (accessibility of the impermeable ferricyanide ion to the respiratory chain, inhibition of membrane ATPase by specific antiserum, and binding of ATPase to the membrane), that the above procedures to prepare envelopes are most likely to cause inversion, with formation of inside-out vesicles.

These results can suggest a reasonable interpretation of the data reported by CurTis et al. ${ }^{8)}$ who demonstrated that the binding in vitro of $\beta$-lactams to the PBPs is similar both in the presence or in the absence of the outer membrane. It is acceptable to assume, on the results obtained by FutAI, that the outer membrane was inside the vesicles, thus not acting as a permeability barrier.

In our opinion, the comparison between the binding affinities in intact cells (outside-out vesicles) and in envelopes (inside-out vesicles) is a simple and reliable method to investigate penetrability of $\beta$-lactam antibiotics. All studies on new compounds should take into consideration not only the affinity profile for the different PBPs (binding in vitro which can be misleading), but also the ability of the antibiotic molecule to reach its target(s) in the intact bacteria.

The results obtained support the validity of our approach.

The observed decreased in vitro affinity for PBP-3 and PBP-1A of the ant $i$-isomer (20 times lower than that of cefotaxime) cannot explain per se the ineffectiveness of this compound as an antibiotic. Indeed, a similar degree of affinity has been demonstrated for the compound without oxime.

Thus, if only the in vitro results were considered, an incorrect interpretation would have been formulated.

The binding studies with intact cells show that, in the case of the compound RU 7-23345 which maintains antibacterial activity although lacking $\beta$-lactamase resistance, the in vivo and in vitro affinity constants for the target PBPs are almost identical. On the contrary, no competition for the PBPs was detected when the anti-isomer of cefotaxime was tested, even at concentrations up to $100 \mu \mathrm{g} / \mathrm{ml}$, in good agreement with the MIC values.

In conclusion our results support the hypothesis that the methoxyimino group in the anti-configuration is responsible for the lack of antibacterial activity because it seems to be associated with the inability of the molecule to come across the outer membrane barrier.

\section{Acknowledgments}

The authors wish to thank Dr. J. Perronet (Roussel-Maestretti, Italy) for supplying the $\beta$-lactam antibiotics utilized in this study. This work has been supported by a grant from the Consiglio Nazionale delle Ricerche $\mathrm{N}^{\circ} \mathrm{CT} 810013204$ to G.A.B. 


\section{References}

1) Maugh, T. H., II: A new wave of antibiotics builds. Science 214: 1225 1228, 1981

2) Cherubin, C. E.; H. C. Neu \& M. Turck, Eds.: Current status of cefotaxime sodium: A new cephalosporin. Rev. Infect. Dis. 4 Suppl. : $281 \sim 488,1982$

3) Labia, R.; A. Kazmierczak, M. Luione \& J. M. Masson: Some bacterial proteins with affinity for cefotaxime. J. Antimicrob. Chemother. 6 Suppl.: 19 23, 1980

4) Sawai, T.; K. Matsuba, A. TAmura \& S. Yamagishi: The bacterial outer membrane permeability of $\beta$-lactam antibiotics. J. Antibiotics 32: 59 65, 1979

5) ZimmermanN, W. \& A. Rosselet: Function of the outer membrane of Escherichia coli as a permeability barrier for $\beta$-lactam antibiotics. Antimicrob. Agents Chemother. 12: 368 372, 1977

6) ZimmermanN, W.: Penetration of $\beta$-lactam antibiotics into their targets enzymes in Pseudomonas aeruginosa: Comparison of a highly sensitive mutant with its parental strain. Antimicrob. Agents Chemother. 18: $94 \sim 100,1980$

7) Curtis, N. A. C.; C. Brown, M. Boxall \& M. G. Boulton: Inhibition of Escherichia coli K12 by $\beta-$ lactam antibiotics with poor antibacterial activity: Interaction of permeability and intrinsic activity against penicillin-binding proteins. Antimicrob. Agents Chemother. 15: 332 336, 1979

8) Curtis, N. A. C.; D. Orr, G. W. Ross \& M. G. Boulton: Affinities of penicillins and cephalosporins for the penicillin-binding proteins of Escherichia coli $\mathrm{K} 12$ and their antibacterial activity. Antimicrob. Agents Chemother. 16: 533 539, 1979

9) Spratt, B. G.: Properties of the penicillin-binding proteins of Escherichia coli K12. Eur. J. Biochem. 72: $341 \sim 352,1977$

10) Reeve, J. N.; D. J. Groves \& D. J. Clark: Regulation of cell division in Escherichia coli: Characterization of temperature sensitive division mutants. J. Bacteriol. 104: 1052 1064, 1970

11) Botta, G. A. \& J. T. PARK: Evidence for involvement of penicillin-binding protein 3 in murein synthesis during septation but not during cell elongation. J. Bacteriol. 145: 333 340, 1981

12) Spratt, B. G.: Escherichia coli resistance to $\beta$-lactam antibiotics through a decrease in the affinity of a target for lethality. Nature (London) 274: 713 715, 1978

13) Botta, G. A. \& D. Buffa: Murein synthesis and $\beta$-lactam antibiotics susceptibility during rod-tosphere transition in a $p b p(T S)$ mutant of Escherichia coli. Antimicrob. Agents Chemother. 19: 891 900, 1981

14) Filip, C.; G. Fletcher, J. L. WulfF \& C. F. Earhart: Solubilization of the cytoplasmic membrane of Escherichia coli by the ionic detergent sodium lauryl sarcosinate. J. Bacteriol 115: 717 722, 1973

15) LaemmLi, U. K.: Cleavage of structural proteins during the assembly of the head of bacteriophage T4. Nature (London) 227: 680 685, 1970

16) Bonner, W. M. \& R. A. Laskey: A film detection method for tritium-labelled proteins and nucleic acids in polyacrylamide gels. Eur. J. Biochem. 46: 83 88, 1974

17) LASKey, R. A. \& A. D. Mills: Quantitative film detection of ${ }^{3} \mathrm{H}$ and ${ }^{14} \mathrm{C}$ in polyacrylamide gels by fluorography. Eur. J. Biochem. 56: 335 341, 1974

18) Nikaido, H.; S. A. Song, L. Shaltiel \& M. Nurminen: Outer membrane of Salmonella. XIV. Reduced transmembrane diffusion rates in porin-deficient mutants. Biochem. Biophys. Res. Comm. 76: 324 330,1977

19) Curtis, N.A. C.; D. C. Orr \& M. G. Boulton: The action of some $\beta$-lactam antibiotics on the penicillin-binding proteins of gram-negative bacteria. Abstracts Proceed. Royal Soc. Chem., pp. 202 204, 1980

20) FutaI, M.: Orientation of membrane vesicles from Escherichia coli prepared by different procedures. J. Membr. Biol. 15: 15 28, 1974 